\begin{tabular}{|c|c|c|}
\hline \multicolumn{3}{|c|}{$\begin{array}{l}\text { Indian Journal of Medical Sciences } \\
\text { (INCORPORATING THE MEDICAL BULLETIN) }\end{array}$} \\
\hline VOLUME 59 & DECEMBER 2005 & NUMBER 12 \\
\hline
\end{tabular}

\title{
AN OUTBREAK OF DENGUE FEVER IN PERIURBAN SLUMS OF CHANDIGARH, INDIA, WITH SPECIAL REFERENCE TO ENTOMOLOGICAL AND CLIMATIC FACTORS
}

R. K. RATHO, B. MISHRA, J. KAUR, ${ }^{\star}$ N. KAKKAR, K. SHARMA

\begin{abstract}
BACK GROUNDS: Dengue viral infection is one of the most important public health problem in tropical countries. AIM: An outbreak of dengue fever was investigated in a periurban slum area of Chandigarh, India, during September to December, 2002. MATERIALS AND METHODS: Blood samples from 218 patients and 30 apparently healthy contacts were tested for dengue-specific immunoglobulin $M$ (IgM) and IgG antibodies including 80 acute samples collected within 5 days of illness were subjected for virus isolation in newborn mice. The average temperature, rainfall, and humidity of the epidemic year were compared with the number of dengue cases. Statistical analysis: statistical significance was found out using $\chi^{2}$-test. RESULTS: A total of 76 cases were positive by either dengue IgM capture assay $(n=57)$ or virus isolation $(n=17)$ or both $(n=2)$. fifteen of nineteen viral isolates subjected for typing by typespecific multiplex reverse transcription-polymerase chain reaction were found to be of dengue virus. High rainfall and humidity with the temperature range from $21^{\circ} \mathrm{c}$ to $33^{\circ} \mathrm{c}$ during the months of August and September might have favored the breeding of mosquitoes, thus leading to an increase in the number of dengue cases in October and November, 2002. CONCLUSION: The present outbreak thus emphasizes the need for continuous sero epidemiological and entomological surveillance for the timely implementation of effective dengue control programme.
\end{abstract}

Key words: Dengue, epidemic, India, Reverse transcription-polymerase chain reaction

Department of Virology, Post Graduate Institute of Medical Education \& Research, *Department of Microbiology, General Hospital, Sector-16, Chandigarh.

\section{Correspondence}

Professor \& Head, Department of Virology, Post Graduate Institute of Medical Education \& Research Chandigarh -160012, India. E-mail: rathopgi@yahoo.com

\section{INTRODUCTION}

Dengue is an important flaviviral disease, with millions of cases occurring every year. ${ }^{[1]}$ There has been considerable increase in number of cases and severity of the disease as well as vast geographic spread, in the past four decades. ${ }^{[2]}$ Dengue fever (DF) complications are caused by four antigenically related, but distinct, dengue virus serotypes (DEN 1-4). ${ }^{[3]}$ Aedes aegypti, the peridomestic mosquito, acts as the principal vector in the dengue virus transmission. ${ }^{[3]}$ More than two billion people are at risk of acquiring dengue infection with an estimated 50 million people infected annually. ${ }^{[1]}$ Kolkata (1963) had experienced, the first major outbreak of dengue hemorrhagic fever (DHF) in India, ${ }^{[4]}$ and subsequently, several outbreaks have been reported in other parts of the country. ${ }^{[5-8]} D_{F}$ once confined to urban areas has now penetrated into the rural setup. ${ }^{[9]}$ In its classical form DF manifests as an acute febrile illness with headache, excruciating joint pain, and myalgia in older children and adults. Whereas, DHF is characterized by hemorrhagic diathesis and may lead to shock (dengue shock syndrome [DSS], which may be fatal. Thrombocytopenia and concurrent hemoconcentration are commonly associated. The degree of morbidity and mortality associated with dengue infectivity necessitates the early confirmation, which could be established either by demonstrating dengue-specific immunoglobulin M ( $\lg M)$ antibodies or detection of virus/viral antigen in clinical samples..$^{[10,11]}$

The present report gives a summary of the results of the virological and entomological investigations conducted and meteorological parameters collected from the department of Meteorology, Chandigarh, during the outbreak of DF in a periurban slum area of Chandigarh, India, during the months of September to December, 2002

\section{MATERIALS AND METHODS}

Blood samples were collected from clinically suspected DF or DHF cases attending various hospitals in Chandigarh and the primary health center of Indira Colony, Panchkula, during the months of September to December, 2002, with prior consent of the patients. The cases of DF and DHF were included as per the criteria laid down by WHO. ${ }^{[11]}$ The detailed clinical and demographic profiles were recorded in a performa for each patient. The majority of the patients were residents of Indira Colony, a peri urban slum area of Chandigarh, which covers an area of $800-1200 \mathrm{~m}^{2}$. More than 2000 families reside in that colony with a population of approx 15, 000.

A total of 218 acute and 8 convalescent blood samples from patients and 30 age- and sex-matched apparently healthy contacts of dengue-positive patients were investigated during the outbreak. Of the 218 patients 72 were from various hospitals in Chandigarh (35 from out patient department and 137 from wards) and samples from 46 patients were collected from the health center at Indira Colony. All acute samples were sent to the Department of Virology on ice for viral diagnosis, and sera were separated aseptically in refrigerated centrifuge and 
stored at $-85^{\circ} \mathrm{C}$ till tested. All the samples were collected after obtaining the informed consent from the patients and contacts.

\section{VIROLOGICAL INVESTIGATIONS}

\section{Serology}

Serum samples from 218 patients and 30 healthy contacts were tested for denguespecific IgM (MAC ELISA) and IgG antibodies by micro-ELISA (PanBio, Australia). Of these 218 patients, paired samples could be collected from 8 patients and were also subjected for dengue-specific $\lg \mathrm{M}$ and $\lg \mathrm{G}$ antibodies.

\section{Virus isolation and identification}

Eighty samples which were obtained within 5 days of illness were inoculated intracerebrally into newborn Swiss albino mice for possible virus isolation. Usually, symptoms of hunch back, less intake of food, and fine tremors leading to paralysis developed on day 8-10 postinoculation. Sick mice were sacrificed and brain tissues were subjected for confirmation by indirect immunofluorescence test using rabbit dengue type-2 polyclonal IgG antibody and goat antirabbit FITC (Dako-Patts) conjugate.

\section{Typing of dengue virus}

Of 19 dengue virus isolates 15 could be subjected for typing by types-specific multiplex reverse transcription-polymerase chain reaction (RT-PCR) as described by Lanciotti et al..[12] after extraction of viral RNA. Viral RNA extracted by using acid guanidium thiacyanate-phenol-chloroform mixture as per the method described by Chome zynski et al. ${ }^{[13]}$
Target viral RNA was then converted to cDNA by using murine moloney leukemia (MuLV) RT and dengue virus down-stream consensus primer homologs to all four dengue serotypes. Subsequent amplification was performed on the resulting cDNA with upstream dengue virus consensus primers in $100 \mathrm{ml}$ reaction mixture containing the following components; $15 \mathrm{mM} \mathrm{KCl,} 10 \mathrm{mM}$ dithiothreitol (DTT), $50 \mathrm{pmol}$ each of upstream and downstream primers, and 2.5 $\mathrm{U}$ of taq polymerase (MBI Fermentas). The reaction mixture was subjected to 1 -hour incubation at $42^{\circ} \mathrm{C}$ and then proceeded with 35 cycles of denaturation $\left(94^{\circ} \mathrm{C}, 30 \mathrm{sec}\right)$, annealing $\left(55^{\circ} \mathrm{C}\right.$ for $\left.1 \mathrm{~min}\right)$ and primer extension $\left(72^{\circ} \mathrm{C}, 2 \mathrm{~min}\right)$.

\section{Dengue virus typing with type specific}

\section{primers}

$10 \mu \mathrm{l}$ of the diluted first PCR products (1:100 in sterile double distilled water) was mixed with all the components described for firs amplification, only the down stream dengue primers were replaced with four type specific primers and DTT and RT were eliminated. The reaction mixture was then subjected to 20 cycles of denaturation $\left(94^{\circ} \mathrm{C}, 30 \mathrm{~s}\right)$, primer annealing $\left(55^{\circ} \mathrm{C}, 1 \mathrm{~min}\right)$, and extension $\left(72^{\circ} \mathrm{C}\right.$ $2 \mathrm{~min}) ; 10 \mu \mathrm{l}$ of reaction product was electrophoresed on $2 \%$ agarose gel.

\section{Antigen demonstration in mosquitoes:}

Female $A$. aegypti mosquitoes were collected from domestic and peridomestic areas to look for the presence of dengue virus antigen. To form each pool, attention was paid to collect the mosquitoes from the interior of the houses of at least one dengue-positive case and six to seven of their immediate neighbors. Each pool consisted of 10-15 mosquitoes. Thus, a minimum of 10 houses of dengue-positive patients' and 60-70 respective neighbors' houses were visited to collect a total of 10 pools of mosquitoes. All collections were done in Indira Colony, from where majority of dengue cases were reported. Head squash preparations were made from four randomly selected mosquitoes from each pool and were tested for dengue antigen by indirect immunofluorescence test as described earlier for virus identification. The pool was considered as positive for dengue antigen when the head squash preparation of any of the representative mosquito showed positive fluorescence.

\section{Studies of the meteorological \\ parameters}

Atmospheric temperature, relative humidity, and rainfall in the Chandigarh city for the epidemic year of 2002, were obtained from the Department of Meteorology, Union Territory, Chandigarh. The average temperature, relative humidity, and average monthly rainfall during the months of January to December were plotted against the number of clinically suspected dengue cases in the year 2002 in order to analyze the seasonal trend of dengue viral infections.

\section{Statistical analysis}

$\chi^{2}$ Square test was applied to find out the statistical significance between the observed values.

\section{RESULTS}

An outbreak of febrile illness occurred in the months of September to December, 2002, in the slum area located at periphery of Chandigarh. Males outnumbered the females with a ratio of $2: 1$. Adults were significantly affected more than the children (207 vs 11) $(P<0.005)$. Figure 1 depicts the age-group distribution of the dengue fever cases.

Patients presented with fever, headache myalgia, and backache. Thrombocytopenia was found in 86 patients (39.4\%), of which $11(12.8 \%)$ developed hemorrhagic manifestations in the form of bleeding gums and hematemasis. The platelet count ranged between 10,000 and $95,000 / \mathrm{mm}^{3}$. The relationship between bleeding manifestation in patients with platelet count $<100,000$ $\mathrm{cmm}$ is shown in Table 1. The difference in the proportion of bleeding manifestations among patients with platelet count in the range of $<20,000,20,000-50,000$ and $>50,000 / \mathrm{mm}^{3}$ was not found to be statistically significant $\quad(P>0.5)$. Hepatomegally was observed in two patients and pleural effusion in one. None of the patients had the features of DSS and no death was recorded in any of these patients.

\section{Virus isolation and typing}

Of the 218 acute blood samples, 80 were obtained within 5 days of illness and were subjected for virus isolation. Thus, dengue

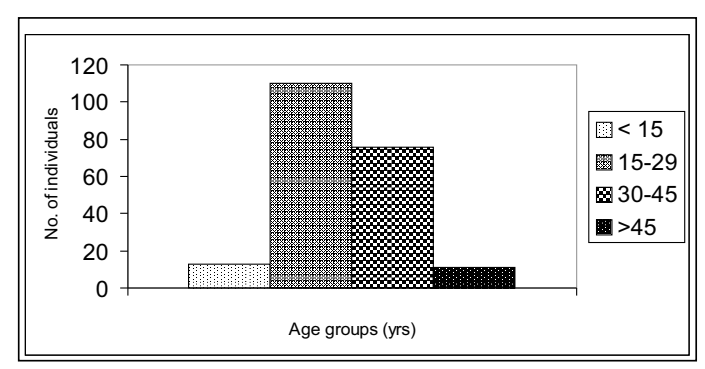

Figure 1: Age-wise distribution of dengue fever cases 
Table 1: Relationship between platelet count and bleeding manifestation in clinically suspected dengue cases

\begin{tabular}{lccc}
\hline $\begin{array}{l}\text { Platelet } \\
\text { count/cmm }\end{array}$ & No. of Cases & $\begin{array}{c}\text { Bleeding } \\
\text { manifestation }\end{array}$ & $\begin{array}{c}\text { No Bleeding } \\
\text { manifestation }\end{array}$ \\
\hline$<20,000$ & 4 & 1 & 3 \\
$20,000-<50,000$ & 41 & 6 & 35 \\
$50,000-<100,000$ & 41 & 4 & 37 \\
Total & 86 & 11 & 75 \\
\hline
\end{tabular}

virus was isolated in 19 samples (23.8\%). Of these, $8,6,4$, and 1 samples were obtained on $1,3,4$, and 5 days of post illness, respectively. Thus, maximum numbers (i.e., 8/19) were obtained on the first day of illness. Seventeen of these nineteen samples were negative for dengue IgM antibody.

Of the 15 mouse brain dengue virus isolates subjected for typing by multiplex RT-PCR, all were found to be of type-2 dengue virus [Figure 2].

\section{Viral serology}

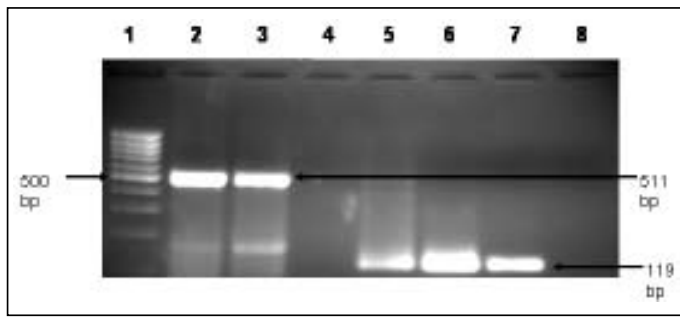

Figure 2: Agarose gel analysis of the multiplex RTPCR product of dengue virus in mice brain isolates. Lane1: Molecular Marker: 100 bp. Lanes 2 and 3: firs PCR product of dengue virus isolates. Lane 4: Neg control (uninfected mouse brain). Lane 5-7: second Lane 8: Neg control (without DNA)

Table 2: Result of viral serology and isolation in clinically suspected dengue fever cases

\begin{tabular}{lccccc}
\hline $\begin{array}{l}\text { Total Number } \\
\text { tested }\end{array}$ & $\begin{array}{c}\text { Dengue IgM } \\
\text {-positive }\end{array}$ & $\begin{array}{c}\text { Dengue virus } \\
\text { isolation }(n=80)\end{array}$ & $\begin{array}{c}\text { Both IgM and } \\
\text { virus isolation }\end{array}$ & $\begin{array}{c}\text { Total } \\
\text { positive }\end{array}$ & $\begin{array}{c}\text { Dengue lgG } \\
\text { positive }\end{array}$ \\
\hline 218 & $57(26 \%)$ & $17(21 \%)$ & 02 & $76(35 \%)$ & $175(80.3 \%)$ \\
\hline
\end{tabular}

Of 218 acute phase sera tested, 58 samples were positive for dengue specific $\lg M$ antibody. Eight convalescent blood samples could be collected from patients whose acute samples were negative for dengue IgM. O them, one patient showed seroconversion in the convalescent sample. Thus, the presence of dengue specific IgM antibodies in acute phase serum samples $(n=58) ; \lg M$ seroconversion in paired sample $(n=1)$ and virus isolation in mouse brain $(n=17)$ comprised the total of 76 (35\%; 76/218) acute dengue confirmed cases [Table 2]. Amongst them, the presence of dengue specific $\mathrm{IgG}$ antibodies in 55 patients $(72.4 \%)$ furthe categorized the cases in to secondary dengue infection. All the healthy contacts were negative for dengue IgM antibody where as $22(73 \%)$ were positive for dengue specific $\lg G$ antibody.

\section{Demonstration of dengue antigen in} mosquitoes

Of the 10 mosquito pools tested for dengue antigen, in head squash preparation of representative mosquitoes dengue antigen positivity was observed in 3 pools.

\section{Meteorological parameters}

[Figure 3] shows the incidence of suspected dengue cases, mean atmospheric temperature, rainfall and humidity during the months of January to December in the epidemic year 2002. Maximum number of patients were seen in the months of October

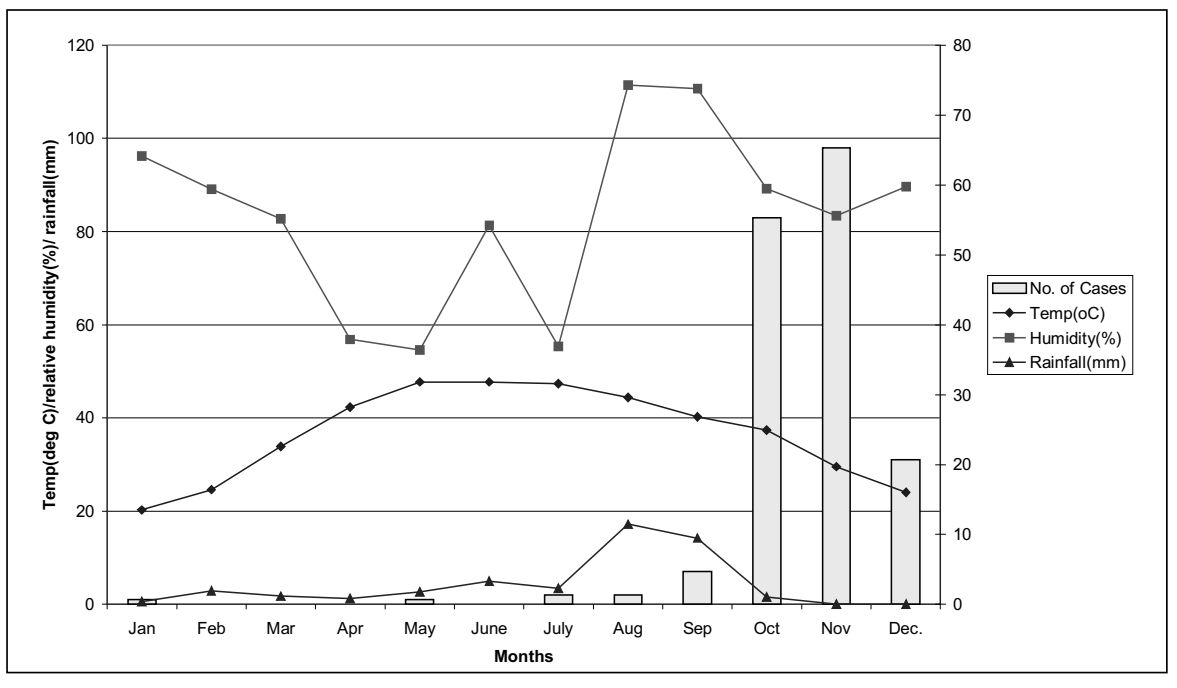

Figure 3: Dengue cases, mean atmospheric temperature, mean relative humldity and average seasonal rainfall during the months of Jan-Dec, 2002

and November when the mean maximum and minimum atmospheric temperatures were $29.4^{\circ} \mathrm{C}$ and $15.2^{\circ} \mathrm{C}$ respectively. The average rainfall and relative humidity during these months were $0.5 \%$ and $57.5 \%$ respectively.

\section{DISCUSSION}

Dengue is well known for its epidemics and its life-threatening complications of DHF or DSS. The epidemics have been experienced in 2-3 year intervals in North India, including Chandigarh. It has already attained endemo-epidemic proportions in many parts of India. In the present outbreak higher number of DF cases were reported in adults than in children aged below 15 years. Similar observation has been reported in DF outbreaks in several other states. ${ }^{[8,14,15]}$ However, DHF cases have been reported mainly in children. ${ }^{[5,16]}$ The male outnumbered the female patients. Patient presentation was in accordance with that of dengue-like illness.
However, no significant corelation was found between the proportion of bleeding manifestation among patients with platelet count in the range of $<20,000,20,000-$ 50,000 , and $>50,000 / \mathrm{mm}_{3}$. The same has also been observed by other workers, which possibly indicated the role of factors other than thrombocytopenia in causation of bleeding manifestation in these patients. ${ }^{[17-19]}$

The serological findings, virus isolation, as well as RT-PCR supported the dengue Type2 viral etiology in this outbreak. IgM antibodies by $\mu$-capture micro-ELISA could be detected in 59 patients, where as 17 additional cases were diagnosed by virus isolation. Secondary dengue infection was significantly higher than primary infection (72.4\% vs $27.6 \%$; $p<0.05$ ). Because more than $80 \%$ cases and $73 \%$ of healthy contacts in the present epidemic had IgG antibodies that indicated the endemicity of dengue viral infection in the locality. 
The present outbreak was owing to dengue type- 2 virus. Dengue fever and DHF, owing to all four dengue serotypes, have been reported from various parts of India. ${ }^{[5,20]}$ However, amongst these type- 2 dengue has been reported most frequently.

All the previous outbreaks of dengue virus infection in Chandigarh indicated the seasonal trend. Outbreaks of DF and DHF have usually been reported during the post monsoon season and continued till onset of winter (August-November). ${ }^{[5]}$ The maximum rainfall and humidity were recorded in the month of August and continued to remain high during September. The average maximum and minimum temperatures were $33.2^{\circ} \mathrm{C}$ and $21.3^{\circ} \mathrm{C}$, respectively, during these months, which might be favorable for breeding as well as maintenance of $A$. aegypti mosquitoes. Similar climatic factors have been observed during dengue fever outbreak in Ludhiana, Punjab. ${ }^{[15]} \mathrm{A}$ higher temperature within mosquito viability has been shown to give way to more infectious mosquitoes which bite more frequently. Epidemic transmission of dengue requires a favorable temperature (>20\%) and stagnant water for breeding of Aedes aegypti. ${ }^{[21]}$

Chandigarh is one of the well-planned and cleaner cities in India. However, in recent years, increase in population density and construction activities as a part of urbanization have led to the sprouting of slums in the periphery of Chandigarh. These peri-urban slum areas are usually over crowded and poorly maintained. With the onset of rain there occurs a spurt in the mosquito population owing to the availability of many favorable conditions for mosquito breeding, such as discarded tyres, tins, and poorly maintained desert coolers. Interestingly, most of the houses in the affected locality had indoor "money plants" grown in open, discarded bottles filled with water, which served as an excellent breeding site for $A$. aegypti. Dengue antigen could be demonstrated in three pools of mosquitoes caught within the vicinity of human-positive cases. Following confirmation of the epidemic, intense door-to-door survey, finding of cases, and implementation of the supportive measures immediately and cleaning the area which was filled with discarded motor tyres containing residual water, were carried out. Simultaneously, the ultra-low-volume malathion aerosol spray was carried out by the Malaria Department, Chandigarh, twice weekly.

The present study thus indicates the need for a continuous, sero-epidemiological, and entomological surveillance in Chandigarh, including its peri-urban slums for timely implementation of an effective control program to prevent such outbreaks in future. Prevention and control includes breaking the transmission cycle of vector mosquitoes or by holding its population at low level. This involves avoiding mosquito bites by use of insecticides and destruction of breeding sites of the principal vector $A$. aegypti which include cleaning of water coolers, storage tanks, tyres, etc. Moreover, it should be stressed that simple throwing of the water from these containers is not sufficient because of the biology of the mosquito egg laying. Usually, female adult Aedes lay eggs at the water-air interface attached to the inner part of the vessel and owing to the slimy nature these egg rafts attach firmly, which requires vigorous scrubbing to detach them. Interestingly, these eggs can withstand drying for long periods and in suitable environment they complete the development. ${ }^{[22]}$ Thus, education of people regarding mosquito breeding habits and its related complications is of paramount importance for success in any such control program.

\section{REFERENCES}

1. Gubler DJ, Clark GG. Dengue/dengue haemorrhagic fever: The emergence of a global health problem. Emerg Infect Dis 1995;1:55-7.

2. Gubler D. Resurgent vector-borne disease as a global health problem. Emerg Infect Dis 1998;4:442-50.

3. Calisher CH, Karabarsos N, Dalrtymple JD, Shope $\mathrm{RE}$, Brandt WE. Antigenic relationship between flaviviruses as determined by cross-neutralization tests with polyclonal antisera. J Gen Virol 1989;70: $37-43$.

4. Ramakrishnan SP, Geljand HM, Bose PN, Sehgal $\mathrm{PN}$. The epidemic of acute haemorrhagic fever, Calcutta, 1963; epidemiological inquiry. Indian J Med Res 1964;52:633-50.

5. Dar L, Broor S, Sengupta S, Xess I, Seth P. The first major outbreak of dengue hemorrhagic fever in Delhi, India. Emerg Infect Dis 1999;5:589-90.

6. Kabilan L, Balasubramanian S, Keshava SM, Thenmozhi V, Sekar G, Tewari SC, et al. Dengue disease spectrum among infants in the 2001 dengue epidemic in Chennai, Tamil Nadu, India. J Clin Microbiol 2003;41:3919-21.

7. Kaur H, Prabhakar H, Mathew P, Marshalla R, Arya M. Dengue hemorrhagic fever outbreak in OctoberNovember 1996 in Ludhiana, Punjab, India. Ind J Med Res 1997;106:1-3.

8. Victor TJ, Malathi M, Guruswami D, Desai A, Ravi
V, Narayansamy G, et al. Dengue fever outbreaks in two villages of Dharmapuri district in Tamil Nadu. Ind J Med Res 2002; 116:133-9.

9. Katyal R, Kumar K, Gill KS. Breeding of Aedes aegypti and its impact on dengue/DHF in rural area. Dengue Bull 1997;21: 95-7.

10. Groen JP, Kloraka J, Nelzing C. Evaluation of six Immuno asays for detection of dengue virus specific Immunoglobulin $M$ and $G$ antibodies. Clin Diagn Lab Immunol 2000; 7:867-71.

11. World Health Organization. Dengue and dengue hemorrhagic fever. Diagnosis treatment prevention and central Head quarters, Geneva, WHO, 1997

12. Lanciotti RS, Calisher CH, Gubler DJ, Change GJ, Vorndam AV. Rapid detection and typing of dengue virus from clinical samples by using reverse transcriptase polymerase chain reaction. J Clin Microbiol 1992;30:545-51.

13. Chomczynski P, Sacchi N. Single step method of RNA isolation by acid guanidium thiocyanate phenol chloroform extraction. Anal Bio- chem 1987; 162:156-9.

14. Mehendale SM, Risbud AR, Rao JA, Banerjee K. Outbreak of dengue fever in rural areas of Parbhani district of Maharastra (India). Ind J Med Res 1991 93:6-11.

15. Ram S, Khurana S, Kaushal V, Gupta R, Khurana $\mathrm{SB}$. Incidence of dengue fever in relation to climatic factors in Ludhiana, Punjab. Indian J Med Res 1998;108:128-33.

16. Cherian T, Ponnuraj E, Kuruvilla T, Kirubakaran C John TJ, Raghupathy P. An epidemic of dengue haemorrhagic fever \& dengue shock syndromein and around Vellore. Ind J Med Res 1994;100:51-6.

17. Narayanan M, Aravind MA, Thilothammal N, Prema R, Sargunam CS, Rex, Ramamurty N. Dengue fever epidemic in Chennai-a study of clinical profile and outcome. Ind Pediatrics 2002;39:1027-33.

18. Gomber S, Ramachandran VG, Kumar S, Agarwal KN, Gupta P, Gupta P, et al. Hematological observations as diagnostic markers in dengue hemorrhagic fever a reappraisal. Ind Pediatrics 2001;38:477-81. 
19. Bethell DB, Gamble J, Lolc PP, Dung NM, Chau $\mathrm{TH}$, Loan HT, et al. Non invasive measurement of micro vascular leakage in patients with dengue hemorrhagic fever. Clin Infect Dis 2001;32:24353.

20. Lall R, Dhanda V. Dengue haemorrhagic fever and dengue - shock syndrome in India. Nat Med J
Ind1996;9:20-3.

21. Patz JA, Epstein PR, Burke TA, Bulbus M. Global climate change and emerging infections. JAMA 1996;275:217-32.

22. Hati AK. Tribe Culicine In: Medical entomology. 1st edition. Calcutta: Allied Book Agency 1979. pp. 40-51. 